\title{
A huge abdomino-pelvis tumour in a prepubertal girl: A case report of dysgerminoma infiltrating both ovaries and uterus in an 11-year-old girl in Maiduguri
}

\author{
Abubakar Garba Farouk, ${ }^{1}$ Abubakar Farate, ${ }^{2}$ Samuel Wabada, ${ }^{3}$ Iro Nkama, ${ }^{1}$ \\ Ado Danazumi Geidam ${ }^{4}$ \\ ${ }^{1}$ Department of Paediatrics; ${ }^{2}$ Department of Radiology; ${ }^{3}$ Department of Surgery, Paediatric Surgery Unit; \\ ${ }^{4}$ Department of Obstetrics and Gynaecology, University of Maiduguri Teaching Hospital, Maiduguri, Borno \\ State, Nigeria
}

\begin{abstract}
Dysgerminoma is one of the rare highly malignant ovarian germ cell tumour. It originate from undifferentiated germ cells that are similar to primordial germ cells, and it is identical to testicular seminoma in males. Despite the tumour being malignant, prognosis is excellent with surgery and adjuvant chemotherapy, with promising results concerning future fertility. In this case, we report an 11-year-old girl with abdominal swelling for 7 years. She had gross abdominal distension, with a huge palpable mass. Abdominopelvic ultrasound scan showed a huge heterogeneous mass measured $9.8 \mathrm{~cm} \times 15.7 \mathrm{~cm}$ and computed tomography showed a huge lobulated mass measured $19.2 \mathrm{~cm}$ x $19.0 \mathrm{~cm}$ x 16.3 $\mathrm{cm}$. Exploratory laparotomy and excision of the mass was done.
\end{abstract}

Correspondence: Abubakar Garba Farouk, Department of Paediatrics, University of Maiduguri Teaching Hospital, Maiduguri, Borno State, Nigeria.

E-mail: farouk649@gmail.com

Key words: Dysgerminoma; ovary; prepubertal girl; uterus.

Conflict of interest: The authors declare no conflict of interest.

Availability of data and materials: All data underlying the findings are fully available.

Ethics approval and consent to participate: No ethical committee approval was required for this case report by the Department, because this article does not contain any studies with human participants or animals. Informed consent was obtained from the patient included in this study.

Consent for publication: The patient's guardians gave their consent to the publication of the paper.

Received for publication: 6 November 2020

Revision received: 23 January 2021.

Accepted for publication: 28 January 2021.

This work is licensed under a Creative Commons Attribution NonCommercial 4.0 License (CC BY-NC 4.0).

(C) Copyright: the Author(s),2020

Licensee PAGEPress, Italy

Annals of African Medical Research 2020; 3:132

doi:10.4081/aamr.2020.132
Ovarian dysgerminoma are uncommon in prepubertal girls. Prognosis depends on the stage at presentation and histology. Multidisciplinary management with a Gynaecologists and Oncologists with joint decision on the need to maintain the child's developmental and reproductive potential as much as possible should aimed at.

\section{Introduction}

Solid ovarian tumours are very rare in the prepubertal girls' population, but when occurred, they are a major source of anxiety especially for the family of the patient. Paediatric ovarian masses account for an estimate incidence of 2.6 cases per 100,000 girls per year, and malignant ovarian tumours account for $0.9 \%$ of all childhood and adolescent malignancies. ${ }^{1,2}$ Dysgerminoma is one of the rare highly malignant ovarian germ cell tumour (MOGT) with a peak incidence in young women. Approximately one-third of all dysgerminomas show KIT mutations and these are associated with advanced stage at presentation. ${ }^{3}$ Dysgerminoma originate from undifferentiated germ cells that are similar to primordial germ cells, and it is identical to testicular seminoma in males. Most cases occur in the $2^{\text {nd }}$ and $3^{\text {rd }}$ decades of life, but $10 \%$ of cases occur in the $1^{\text {st }}$ decade of life. ${ }^{4}$ Most patients with dysgerminoma (75\%) are diagnosed with early-stage disease, and in such situations surgery alone is curative, and the prognosis is usually excellent, ${ }^{5}$ however, there is a significant dilemma with the management of advanced disease in children and adolescents. ${ }^{6} \mathrm{~A}$ rare case of ovarian dysgerminoma in an 11-years-old prepubertal school girl who was referred to the Paediatric oncology unit of the University of Maiduguri Teaching Hospital is being reported. The paucity of information concerning the frequency and pattern of malignant ovarian tumours including dysgerminoma in children in most Nigerian literature and the rarity of this malignancy in prepubertal children and the recognized controversies in its management prompted us to report our experience.

\section{Case Report}

An 11-years-old girl presented with complaints of abdominal swelling of 7 years duration. Her parents reported a gradually increasing abdominal distention from the age of 4 with no other symptoms until 3 months before presentation when she developed abdominal pain, more in the lower abdomen associated with progressive weight loss, and decreased appetite. The patient also had occasional urine retention, which resolved spontaneously, no dysuria, no passage of stones or fleshy material in the urine. The 
patient was yet to attain menarche, no breast enlargement, no abnormal discharge per vagina.

Physical examination showed a chronically ill-looking, wasted child, pale, not jaundiced, acyanosed, and no dysmorphic facie with Tanner stage IIB of breast development. She weighed $27 \mathrm{~kg}$ ( $3^{\text {rd }}$ percentile), and height of $140 \mathrm{~cm}\left(25^{\text {th }}\right.$ percentile $)$. The patient had a soft, grossly distended, and non-tender abdomen, with a large firm palpable mass at the suprapubic region extending to the epigastrium, with a nodular surface and mobile. No demonstrable ascites. Haemoglobin, alpha-fetoprotein, and human chorionic gonadotropin beta subunit levels were normal.

Computed tomography scan showed a huge lobulated abdominopelvic mass measured $19.2 \mathrm{~cm} \times 19.0 \mathrm{~cm} \times 16.3 \mathrm{~cm}$ and extended from the pelvis to the epigastric region and laterally to the abdominal and pelvic side walls. Central specks of calcifications were also present. A small area of hypodensity was also noted within the mass, suggestive of necrotic area. The lesion did not enhance significantly after intravenous contrast injection (Figure 1).

The preoperative diagnosis of this case was a teratoma to rule out fibrolipoma. Subsequently, an exploratory laparotomy was performed under general anesthesia, and excision of a huge rubbery mass from the pelvis was done. Tumour was mobilized bluntly on sides (after ligating both uterine arteries) and also from the rectum. The ureter on the left was dissected off the tumour wall before the tumour was excised in piecemeal with part of the bladder wall. The distal component was excised off the proximal third of the vagina. Grossly, the tumour weighed $1900 \mathrm{~g}$ (Figure 2). Histologic section of the mass showed tissue displaying malignant neoplasm composed of aggregate strands and island of fairly uniform large cells separated by delicate fibrous septae that are infiltrated by lymphocytes. The neoplastic cells have round to oval nuclei some of which have prominent eosinophilic nucleoli and moderately pale cytoplasm. Areas of necrosis were also present (Figure 3). Based on histopathologic features, a final diagnosis of dysgerminoma was rendered. The patient tolerated the surgical procedure well without complication and was transferred to Paediatric oncology unit for chemotherapy on postoperative day seven. She had two

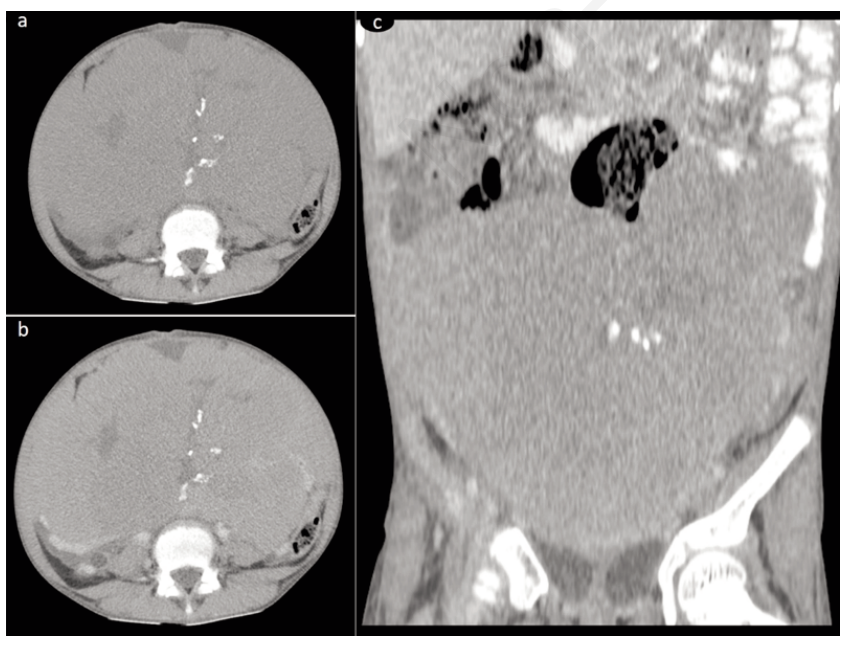

Figure 1. CT images: a) Axial pre-contrast scan showing huge intraabdominal mass with central specks of calcification; b) Axial post-contrast scan showing no significant contrast enhancement; c) Coronal reformatted image demonstrating the extent of the mass from pelvic cavity to epigastrium and laterally to the abdominal and pelvic side walls. cycles of adjuvant chemotherapy before discharge. The patient was lost to follow up after two cycles of the adjuvant chemotherapy. All efforts at locating the patient were unsuccessful as she was said to have been residingt in a remote village which is not readily accessible due to Boko Haram insurgency in North-eastern Nigeria.

\section{Discussion}

Dysgerminomas are the most common ovarian malignancies in children, constituting $9.5 \%$ to $11 \%$ of childhood ovarian tumours and $24.5 \%$ of paediatric ovarian malignancies. ${ }^{7}$ There is an increased frequency of dysgerminomas among patients with genetically abnormal gonads. ${ }^{8,9}$ The rarity of paediatric ovarian malignancies was reported by Ajani et al. ${ }^{10}$ as only 24 cases of ovarian neoplasms were seen under the age of 15 years over a 22 -years period (1991-2003) at University College Hospital, Ibadan. Dysgerminoma was found to be the most common primary malig-

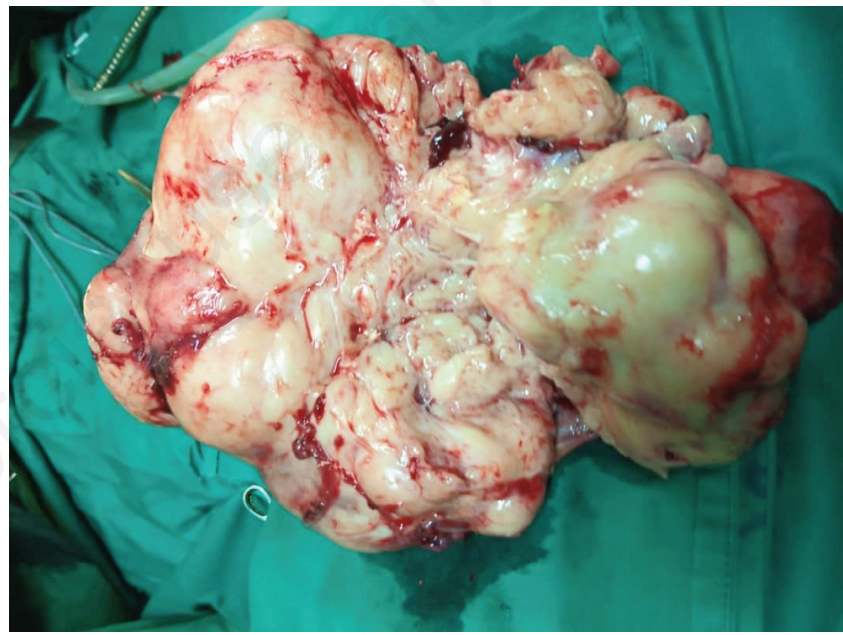

Figure 2. Gross picture showing both ovaries involved with a huge solid capsulated mass.

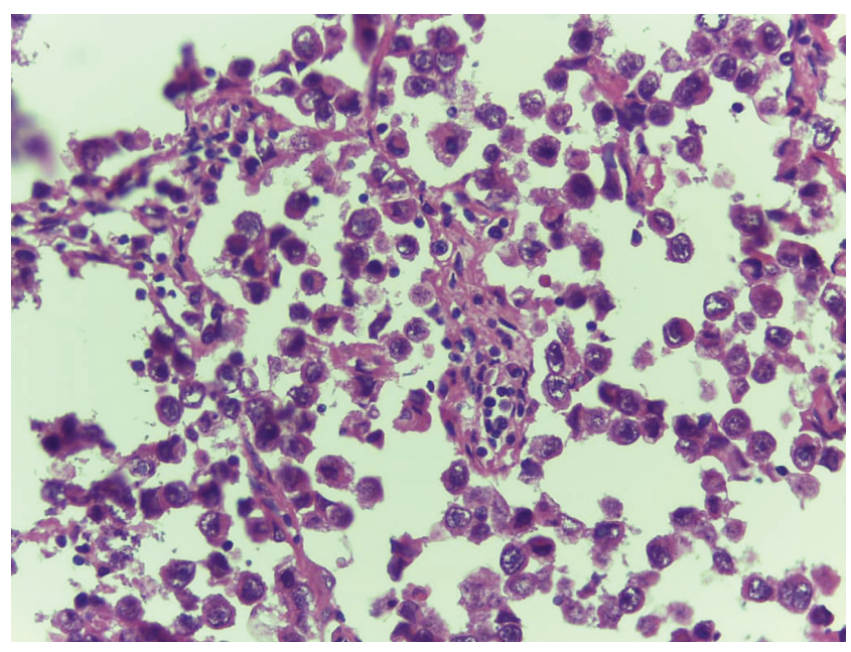

Figure 3. Photomicrograph section shows nests of fairly uniform polygonal cells with moderate to scanty cytoplasm separated by fibrous septae infiltrated by mature lymphocyte. $\mathrm{H}$ and $\mathrm{E} x \mathbf{1 0 0}$. 
nant paediatric ovarian tumour in Nigerian children. ${ }^{9}$ However, there were only two reported cases in the Nigerian literature over the past 15 years. ${ }^{6,10}$ A pure dysgerminoma is endocrinologically inactive. Signs of pronounced hormonal activity indicate the presence of a functioning component, placing the tumor into a mixed germ cell category. ${ }^{11}$ Ovarian tumours including malignancies can present with diverse signs and symptoms, and most often, the clinical presentation does not permit differentiation between benign and malignant tumour as found in the index case. The rate of bilaterality as found in the index case is reported to be $5 \%$ to $20 \%{ }^{11}$ Abdominal pain is the most common symptom encountered, ${ }^{10}$ as we found in our patient. A mobile, palpable abdominal mass is the most frequent physical finding, ${ }^{10}$ as we also observed in our patient. Grossly, dysgerminomas are rubbery, gray, smooth, or bosselated and are surrounded by a dense capsule. The cut surface is soft and homogeneous and has a brainlike consistency, ${ }^{11,12}$ that is similar to what was found in the index case. Elevated LDH can be an early clinical sign of an ovarian dysgerminoma. However, it is not all dysgerminomas that produce LDH, and elevated LDH is often regarded as a nonspecific finding. Our patient had a normal LDH levels.

The management of childhood ovarian tumour must be balanced with the desire to maintain the child's reproductive and developmental potential as much as possible. Vicus et al. published data of the occurrence of pure ovarian dysgerminomas with $72.3 \%$ at stage I, $4.6 \%$ at stage II, and $21.5 \%$ at stage III disease. The initial treatment employed was surgery with $72.2 \%$ of the patients undergoing unilateral oophorectomy and $21.5 \%$ bilateral oophorectomy with or without hysterectomy. ${ }^{13}$ The indication for bilateral oophorectomy and hysterectomy in our case was intrasurgically made. The reason for that decision was a macroscopically visible infiltration of both ovaries and the uterus which coalesce to constitute the huge tumour mass. Although the main aim is fertility-preserving surgery and is possible in $70 \%$ of cases, ${ }^{13,15}$ the indication for bilateral oophorectomy and hysterectomy in our case was inevitable. We could not see any remote possibility of sparing the infiltrated uterus and both ovaries without putting the child into risk of a further growing of the tumour and probably leading to metastasis into other organs and there by jeopardizing the survival of the child. Similar to our case Nishio et al. did radical surgery and administered chemotherapy in advance stages of ovarian dysgerminoma. ${ }^{16}$ In contrast to this Vicus et al. showed that fertilitysparing surgery in women with pure ovarian dysgerminoma led to 8 in 65 cases to 12 pregnancies and 12 live births. ${ }^{13}$ Lymph node metastasis is present in $28 \%$ of dysgerminomas and is significantly associated with poor survival. ${ }^{15-18}$ In order to evaluate the prognosis and find adequate therapeutic options lymphadenectomy is indicated. The result of the lymphadenectomy in our case was negative for tumour cells. Adjuvant chemotherapy in combination with initial surgery shows promising results concerning outcome and fertility. We believe that our report on the challenges of diagnosis and treatment in this case can help clinicians to better understand and manage this kind of malignant tumour.

\section{Conclusions}

Ovarian dysgerminoma are uncommon in girls below the age of 12. Pain and abdominal mass are the most common modes of presentation. Dysgerminoma is the most common malignant ovarian tumour. Prognosis depends on the size of the tumor, stage at presentation and histology of the tumour. Conservative surgery should be aimed at during the initial treatment in children and adolescents who are yet to start their reproductive life. Adoption of multidisciplinary management with a Gynaecologists and Oncologists with joint decision on the need to maintain the child's reproductive and developmental potential as much as possible should be the aim.

\section{References}

1. Gupta B, Guleria K, Suneja A, et al. Adolescent ovarian masses: A retrospective analysis. J Obstet Gynaecol 2016;36:515-7.

2. Al Jama FE, Al Ghamdi AA, Gasim T, et al. Ovarian tumours in children and adolescents - a clinical study of 52 patients in a university hospital. J Pediatr Adolesc Gynecol 2011;24:25-8.

3. Cheng L, Roth LM, Zhang S et al. KIT gene mutation and amplification in dysgerminoma of the ovary. Cancer 2011;117:2096-103.

4. Merino MJ, Jaffe G. Age contrast in ovarian pathology. Cancer 1993;71:537-44.

5. Heo SH, Kim JW, Shin SS, et al. Review of ovarian tumours in children and adolescents: Radiologic-pathologic correlation. Radiographics 2014;34:2039-55.

6. Okunade KS, Yakubu CI, Osuji N, Salako O. A rare case of ovarian dysgerminoma in a 6-year old child in Lagos: A case report. Trop J Obstet Gynaecol 2017;34:246-9.

7. Ehren IM, Mahour GH, Isaac H. Benign and malignant ovarian tumours in children and adolescents: A review of cases. Am J Surg 1984;147:339

8. von Allmen D. Malignant lesions of the ovary in childhood. Semin Pediatr Surg 2005;14:100-5.

9. Vidal IS, Soares LS, Gurgel KB, et al. Hot Flushes in a 15Year-Old Girl Post Treatment of Bilateral Ovarian Dysgerminoma: A Case Report. Obstet Gynecol Cases Rev 2018;5:120.

10. Ajani MA, Aramide KO, Ajani TA, et al. Childhood ovarian neoplasms in Ibadan, South-Western Nigeria. Niger Med J 2016;57:164-6.

11. Roberts OA, Oranye BC. Ovarian dysgerminoma in an adolescent: A case report. Afr J Med Sci 2013;42:197-200.

12. Breen J, Denehy T, Taylor RR. Pediatric Ovarian Malignancies. Glob Libr Women's Med 2008; doi 10.3843/GLOWM.10251.

13. Vicus D, Beiner ME, Klachook S, et al. Pure dysgerminoma of the ovary 35 years on: a single institutional experience. Gynaecol Oncol 2010;117:23-6.

14. Biswajit D, Patil CN, Sagar TG. Clinical presentation and outcome of paediatric ovarian germ cell tumour: a study of 40 patients. J Paediatr Haematol Oncol 2010;32:54-6.

15. Hyseni N, Llullaku S, Jashari H et al. Advanced ovarian dysgerminoma infiltrating both ovaries and uterus in a 7-year-old girl. Case Rep Oncol Med 2014;2014:910852.

16. Nishio S, Ushijima K, Fukui A, et al. Fertility-preserving treatment for patients with malignant germ cell tumours of the ovary. J Obst Gynaecol Res 2006;32:416-21.

17. Kumar S, Shah JP, Bryant CS, et al. The prevalence and prognostic impact of lymph node metastasis in malignant germ cell tumours of the ovary. Gynecol Oncol 2008;110:125-32.

18. Andres MM, Costa E, Canete A, et al. Solid ovarian tumours in childhood: a 35-year review in a single institution. Clin Transl Oncol 2010;12:287-91. 